\title{
Oportunidades de autorregulação em contexto pré-escolar: percepções e práticas de educadores de infância
}

\section{Resumo}

\author{
Janete Silva Moreira ${ }^{1}$ \\ http://orcid.org/0000-0001-7504-0291 \\ Ana Margarida Veiga Simão ${ }^{1}$ \\ https://orcid.org/0000-0003-3652-5573.
}

Conhecendo as competências das crianças para autorregular as tarefas cotidianas e seguindo uma perspetiva sociocognitiva, procuramos compreender as percepções de educadores de infância sobre a promoção da autorregulação de tarefas. Pretendíamos também conhecer as práticas educativas que promovem oportunidades para as crianças autorregularem tarefas na educação pré-escolar. Realizamos um estudo de casos múltiplos com quatro contextos ao longo de seis meses, entrevistando as educadoras e observando as práticas com os seus grupos de crianças. Nas entrevistas, o aspecto mais destacado pelas educadoras refere que é preciso respeitar o desenvolvimento individual, sendo também necessário potenciá-lo. Nas observações sistemáticas, identificamos 739 indicadores de autorregulação que avaliamos em quatro dimensões: controle emocional e comportamental, controle cognitivo, atitudes prossociais e motivação para a autorregulação. Os resultados permitiram relacionar as dimensões de autorregulação com o discurso das educadoras e as oportunidades observadas nos contextos. As oportunidades que remetiam para o controle emocional e comportamental e o controle cognitivo foram as mais expressivas, no geral, e as de motivação para a autorregulação estiveram em maior número, mas só num contexto. A investigação permite refletir sobre a intencionalidade pedagógica num ambiente onde (quase) tudo é brincar, mas também sublinha a pertinência de desenvolver a autonomia das crianças na educação pré-escolar em graus de liberdade cada vez maiores. Nas implicações do estudo, refere-se que é preciso apoiar os educadores nas suas práticas para que criem oportunidades nos contextos que permitam às crianças deter o papel ativo na construção do conhecimento.

\section{Palavras-chave}

Autorregulação - Educação pré-escolar - Estratégias pedagógicas - Educadores de infância.

1- Universidade de Lisboa, Faculdade de Psicologia, Lisboa, Portugal.

Contatos: janetepsilva@gmail.com; amsimao@psicologia.ulisboa.pt 


\title{
Opportunities for self-regulation in preschool: teachers' perceptions and practices
}

\begin{abstract}
Following a socio-cognitive perspective, preschool children have competencies to selfregulate daily tasks. Considering this, we questioned preschool teachers' perceptions about the promotion of self-regulation in this context. We also observed educational practices, given children where were opportunities to self-regulate preschool tasks. This was a multiple case study with four schools. We interviewed teachers and observed practices along six months. In the interviews, the most quoted issue was the need to respect children's individual development, and also the importance of promoting it. In systematic observations, we identified 739 self-regulation indicators categorized in four dimensions: emotional and behavioral control, cognitive control, pro-social attitudes, as well as motivation to self-regulation. The results linked self-regulation dimensions to teachers' speech and the opportunities children were provided with. The most expressive dimensions were emotional and behavioral control and cognitive control. The motivation to self-regulation dimension was the most emphasized, but only at one school. The discussion reflects how preschool play should have a pedagogical intentionality, but it also highlights that children's autonomy can be developed in progressively higher degrees of freedom. The pedagogical implications of our study include teachers' practices so they can promote opportunities for self-regulation. In fact, children should have opportunities to play a central role in their learning process.
\end{abstract}

\section{Keywords}

Self-regulation - Preschool - Pedagogical strategies - Preschool teachers.

\section{Autorregulação na segunda infância}

0 desenvolvimento de competências autorregulatórias das crianças da segunda infância tem emergido como uma área de interesse internacional na educação. Com o aumento do número de anos de frequência escolar obrigatória, a competência do aprendente de se autorregular é destacada como uma componente fundamental para o envolvimento e sucesso escolares (MCCLELLAND; WANLESS, 2015). Considerando a aprendizagem como um conceito multidimensional segundo a perspectiva sociocognitiva de Zimmerman (2013), os processos envolvidos na aprendizagem autorregulada requerem que o aprendente esteja consciente da sua utilização, mobilizando aspectos cognitivos, metacognitivos, motivacionais e emocionais em função dos seus objetivos e metas de aprendizagem. As fases de autorregulação cumprem um ciclo de ação, continuamente aberto 
a novos desenvolvimentos, com recuos e avanços, sempre diferentes, porque enriquecidos pelo contexto em que ocorrem, pela experiência anterior e pelos resultados que se vão alcançando. Na segunda infância, o desenvolvimento da autorregulação implica mais do que o autocontrole, porque a vontade de aprender é sobretudo natural e não deliberada. A autorregulação e o autocontrole estão ligados conceitualmente, uma vez que ambos dependem do desenvolvimento, mas diferem no grau; a primeira é adaptativa face a mudanças, podendo ser considerada uma forma mais madura de controle que implica o uso da reflexão (KOPP, 1982). Nesta fase, a criança já tem um potencial para o desenvolvimento de respostas de organização, de modificação e regulação dela própria e, por volta dos 4 anos, utiliza competências que envolvem a instrospecção e a consciencialização, tornando-se mais responsável e consciente dos seus pensamentos e ações (BRONSON, 2000). A maleabilidade das estruturas cerebrais que caracteriza esta fase, sobretudo ao nível do córtex pré-frontal (planejamento, atenção, memória de trabalho, tomada de decisão e controle inibitório) cria uma janela de oportunidades no desenvolvimento das competências autorregulatórias. A investigação tem explicado como as crianças se autorregulam pela relação entre a aprendizagem e o desenvolvimento humano: esta faixa etária caracteriza-se pela centração na ação em deterioramento do pensamento (SÁIZ; CARBONERO; ROMÁN, 2014) e pela utilização de uma conduta verbal que organiza e regula o comportamento (LOPES DA SILVA, 1985). É, então, necessário fazer um ensino explícito das estratégias autorregulatórias (VEIGA SIMÃO, 2013), nomeadamente de planejamento, monitorização e avaliação, porque as crianças têm dificuldade de especificar o conteúdo do seu pensamento e tendem a pensar retroativamente sobre a ação. A exteriorização dos pensamentos e a explicação dos comportamentos surge associada à linguagem ou private speech, que se define pela prática de as crianças falarem em voz alta para si próprias enquanto desempenham uma tarefa (HARRIS, 1990). A autorregulação é, pois, uma skill simultaneamente desenvolvida e aprendida, estando intimamente relacionada com a maturidade das crianças e as oportunidades dos contextos onde elas estão inseridas (SKIBBE et al., 2011). A percepção positiva sobre o contexto (WILLIFORD et al., 2013) e a possibilidade de desenvolver atividade física e competências escolares (BECKER et al., 2014) estão também relacionadas com a autorregulação. Mas ela não deve ser vista como um acréscimo nos conteúdos curriculares, é antes uma fusão (MARTIN; KRAGLER, 2012): quanto mais o projeto pedagógico integrar atividades que desenvolvam competências cognitivas e socioemocionais, mais evidentes serão os efeitos de transferência para outras áreas da vida (HUBERT et al., 2015). A modelagem e o treino de competências tornamse, assim, práticas educativas influenciadoras das atitudes, emoções e motivações das crianças (WOOD; BENNETT, 2001), porque lhes permitem aprender a organizar-se e a modificar a ação, controlar a sua atenção e o esforço, regular as relações sociais com os pares, manipular objetos e cumprir regras da sala (DEMIRTAS, 2013; FERNANDES, 2012).

\section{Dimensões de autorregulação}

Bronson (2000) descreve o desenvolvimento da autorregulação em quatro dimensões (controle emocional e comportamental, controle cognitivo, atitudes prossociais 
e motivação para a autorregulação) que contribuem para compreender como se podem estruturar as oportunidades para as crianças autorregularem as tarefas do contexto préescolar. À medida que as crianças vão interiorizando normas comportamentais e de expressão das emoções, elas se tornam gradualmente mais capazes de exercer o controle interno de si próprias (controle emocional e comportamental), podendo ser envolvidas na constituição do espaço das salas, na organização adaptável e reversível do meio físico e na arrumação dos materiais (BULUT PDÜK; YILDIZBAS; AYGUN, 2014). A flexibilidade e a funcionalidade dos espaços tornam-se, assim, aspectos centrais para a adequação pedagógica e a estruturação psicológica dos intervenientes (RENTZOU, 2014; ŞAHIN; DOSTOĞLU, 2014).

Uma vez que as estruturas cognitivas estão ainda em maturação, as funções executivas têm um papel primordial na mobilização das competências metacognitivas (BRYCE; WHITEBREAD; SZÜCS, 2014). Este aspecto é corroborado por educadores de infância, professores e investigadores que afirmam que as crianças se vão tornando mais orientadas para os objetivos, conseguindo pensar por si próprias, analisar tarefas específicas, tomar decisões e resolver problemas - conhecimento metacognitivo (PISCALHO; VEIGA SIMÃO, 2014a). A liberdade para fazer escolhas e tomar decisões são oportunidades muito importantes para as crianças se apropriarem das tarefas, podendo ocorrer em atividades dentro da sala, no exterior (MCCLINTIC; PETTY, 2015) ou em brincadeira livre (KONTOS, 1999), existindo sempre uma certa orientação do educador para estimular a curiosidade e a iniciativa da criança (PISCALHO; VEIGA SIMÃO, 2014a). As percepções do educador e a sua experiência prévia são influenciadoras da forma como integra, por exemplo, as tecnologias de informação e comunicação na sala (MASOUMI, 2015) ou potencia a literacia emergente (ONCUA; UNLUER, 2015; SANDVIK; DAAL; ADÈR, 2014). A investigação nesta área tem-se constituído como um apoio aos educadores para promoverem o desenvolvimento metacognitivo das crianças (WHITEBREAD; COLTMAN, 2010) e como uma oportunidade de formação contínua (HADLEY; WANIGANAYAKE; SHEPHERD, 2015; PISCALHO; VEIGA SIMÃO, 2014b).

A atenção ao outro e o envolvimento voluntário em atividades cooperativas são competências que se tornam, naturalmente, mais salientes durante a idade pré-escolar. Mas o desenvolvimento de competências sociais e emocionais está também relacionado com a adaptação do espaço físico, como no caso das áreas temáticas, que contribuem para a forma como as crianças alcançam as suas metas de aprendizagem (CUETO; LEÓN; MIRANDA, 2016).

A fim de dar, progressivamente, maior autonomia às crianças, os educadores devem focar-se mais no processo do que no produto das aprendizagens, podendo, para isso, recorrer à modelagem e à monitorização (PERRY; VANDEKAMP, 2000). A empatia é também salientada pela investigação como uma importante competência do educador neste âmbito (PECK; MAUDE; BROTHERSON, 2015). Por outro lado, o feedback dado às crianças acerca do seu desempenho funciona como um reforço motivacional para a relação com o adulto e para a prossecução na ação (MÄÄTTÄ; JÄRVELÄ, 2013). A validação de experiências influencia, ainda, o clima emocional da sala e contribui para a adoção de comportamentos adaptativos de autorregulação (FUHS et al., 2013). 


\section{Contexto pré-escolar português}

Dada a necessidade de educar as crianças para uma verdadeira maturidade humana, cognitiva e emocional e o quadro legal português (PORTUGAL, 1997a, 1997b), a educação pré-escolar é um contexto privilegiado para o desenvolvimento das competências autorregulatórias. Acresce, ainda, o fato de as Orientações Curriculares (MINISTÉRIO DA EDUCAÇÃO, 2016) e as Metas de Aprendizagem (MINISTÉRIO DA EDUCAÇÃO, 2010), enquanto documentos orientadores das práticas para este ciclo de ensino, preverem o desenvolvimento da autonomia e a responsabilização da criança, enquanto elemento ativo e construtor da sua aprendizagem. É, contudo, necessário compreender a aprendizagem autorregulada como um conjunto de competências de que a criança vai se dotando ao longo do desenvolvimento, mesmo antes da escolaridade obrigatória, e que inclui tanto dimensões de regulação emocional como de interação social. Estas últimas assumem particular relevância durante a segunda infância, dado que a aprendizagem se realiza mais pela apreensão dos contextos e relações neles estabelecidas do que pela capacidade cognitiva (BANDURA, 1997). Assim sendo, as concepções dos educadores sobre a aprendizagem das crianças e os modelos educativos adotados são determinantes para a forma como elas processam e integram novos conceitos (BROSTRÖM et al., 2015). Consideram-se, inclusivamente, mais eficazes os modelos que partem da experiência ou "curiosidade natural da criança e do seu desejo de saber e compreender porquê" (MINISTÉRIO DA EDUCAÇÃO, 2016, p. 88). Em Portugal, o número de anos de escolaridade obrigatória tem aumentado e as crianças ingressam em instituições educativas cada vez mais cedo. 0 Ministério da Educação prevê, inclusivamente, que o acesso à educação pré-escolar estatal esteja disponível para todas as crianças a partir dos 3 anos, em 2017.

As questões de investigação a que nos propomos responder foram: Quais as percepções dos educadores sobre as práticas que promovem a autorregulação de tarefas? Quais práticas educativas promovem oportunidades para as crianças autorregularem a execução de tarefas na educação pré-escolar?

\section{Método}

Este é um estudo de casos múltiplos, cujo design permite dar significado aos contextos na sua especificidade, com descrições detalhadas de nível prático e conceptual (YIN, 2009). Procuramos compreender como é que as crianças apreendem e gerem a sua experiência cotidiana, através da análise cruzada entre os casos e do estabelecimento de contrastes e comparações. Neste tipo de investigação, as características do investigador são especialmente importantes, devendo incluir a empatia e a humildade para ser aceito no contexto, tomar contato com a rotina, os hábitos e comportamentos e tornar-se uma presença familiar. Nos estudos de caráter indutivo são também tidos em conta os efeitos de treino do observador. Por estas razões, o trabalho de campo foi extenso e intenso e recorreu a grelhas de registo a partir das quais se construiu o diário de campo - anotações, esquemas e esboços (AMAD0; FREIRE, 2013). 


\section{Participantes}

Foram selecionados quatro participantes através de um método intencional com os requisitos: ser formado em educação de infância, ter prática profissional e liderar, naquele ano letivo, um grupo de educação pré-escolar. As educadoras eram do sexo feminino e de nacionalidade portuguesa. As escolas estavam localizadas na área metropolitana de Lisboa, em Portugal. 0 nível socioeconômico das famílias variava entre baixo e médioalto. Cada grupo tinha, no máximo, 24 crianças. Outros dados de caracterização podem ser consultados na Tabela 1.

Tabela 1 - Participante, experiência profissional, caráter da escola e características do grupo de crianças

\begin{tabular}{ccccccc}
\hline Participante & Experiência profissional & Escola & Grupo de crianças \\
\hline Contexto A & 10 anos & Privada & Multietário (3 a 5 anos) \\
\hline Contexto B & 4 anos & Privada & 5 anos \\
\hline Contexto C & 9 anos & $\vdots$ & Privada & Multietário (3 a 5 anos) \\
\hline Contexto D & 28 anos & $\vdots$ & Estatal & $\vdots$ & 5 anos \\
\hline
\end{tabular}

Fonte: dados da pesquisa.

0 contexto A era uma instituição particular de solidariedade social que integrava as valências de berçário, creche e jardim de infância no mesmo edifício. Existiam quatro grupos de educação pré-escolar, todos multietários. Quatro das crianças eram do sexo feminino e duas do masculino. A escola que correspondia ao contexto B abrangia alunos desde o berçário ao $2^{\circ}$ ciclo, em edifícios distintos. Nesta escola, era o único grupo de 5 anos. Doze das crianças eram do sexo feminino e doze do masculino. 0 contexto $\mathrm{C}$ era uma instituição particular de solidariedade social com as valências de berçário, creche e jardim de infância, no mesmo edifício. 0 grupo era multietário, entre outros três grupos de pré-escolar; oito crianças eram do sexo feminino e três do sexo masculino. 0 contexto D funcionava numa escola de $1^{\circ}$ ciclo, num edifício apropriado à educação pré-escolar. No total, haviam três grupos com crianças de 5 anos. Oito das crianças participantes eram do sexo feminino e nove do masculino. Uma criança estava referenciada com necessidades educativas especiais.

\section{Instrumentos}

Para conhecer as percepções dos educadores sobre a promoção da autorregulação junto das crianças e recolher outros dados de caracterização, foi realizada uma entrevista semiestruturada individual com cada educadora. 0 guião da entrevista estava organizado em quatro blocos (AMAD0; FERREIRA, 2013, Figura 1). Os objetivos da entrevista incluíam: tomar contato com o percurso formativo e profissional da educadora; conhecer as suas práticas educativas no contexto e inquirir sobre a familiaridade com o construto de autorregulação. 
Figura 1 - Blocos da entrevista e questões orientadoras

Percurso académico e profissional - Como foi o seu discernimento vocacional na
escolha da profissão? Que oportunidades de formação tem tido na sua atividade
profissional.
Organização de estratégias de aprendizagem na prática - Quais são os desafios e
potencialidades das crianças com quem trabalha? Que papel desempenham as
Orientações Curriculares e as Metas de Aprendizagem na sua prática?
Promoção da autorregulação na Educação Pré-escolar - De que forma procura criar
oportunidades de autorregulação das crianças? Pode exemplificar com atividades
desenvolvidas nesse sentido?
Intenções de melhoria profissional - O que pensa da oportunidade de receber feedback
sobre a sua prática? De que forma considera que a experiência de outro profissional da
Educação a pode auxiliar?

Fonte: Amado e Ferreira (2013), tendo em conta os objetivos do estudo.

A fim de identificar as práticas promotoras de oportunidades para as crianças autorregularem tarefas, foram realizadas observações sistemáticas. Construiu-se uma grelha de registo a partir das notas de campo das observações naturalistas e de outros instrumentos de registo (VEIGA SIMÃO, 2002; WHITEBREAD et al., 2009). A grelha continha informações sobre a atividade (como as crianças estão organizadas: pequeno grupo, grande grupo ou atividades no exterior da sala), a tarefa (o que estão a fazer), as observações (como a educadora interage com o grupo), os comportamentos das crianças e respectivas verbalizações. A opção por este instrumento apoiou-se na necessidade de explorar a relação dinâmica entre as crianças e o meio e de contextualizar o estudo dos fenômenos educacionais (GROTH, 2010).

\section{Procedimentos}

Os participantes foram contatados pessoalmente e foi requerida autorização escrita à direção das escolas e aos pais das crianças. Os procedimentos éticos e deontológicos foram acautelados e o anonimato dos participantes protegido, conforme aprovação da Comissão Especializada de Deontologia. As entrevistas tiveram lugar em espaço próprio onde só a investigadora e a educadora estiveram presentes; depois de apresentados os objetivos da entrevista, obteve-se o consentimento informado. A duração variou entre 29:50m e 47:30m. As entrevistas foram transcritas, analisadas e, depois, destruídas. Os momentos de observação foram combinados, tendo em conta a disponibilidade dos participantes e as atividades. 0 tempo de observação foi de oito períodos por grupo. 0 período da manhã era entre as $9 \mathrm{~h} 30$ e as $12 \mathrm{~h}$ e o da tarde entre as $13 / 14 \mathrm{~h}$ e as $15 / 16 \mathrm{~h}$. A observadora acompanhou as atividades, aproximando-se das crianças e interagindo o menos possível; anotou todas as informações durante e imediatamente após as observações. A recolha decorreu ao longo de seis meses. 


\section{Análise de dados}

A análise de conteúdo foi do tipo misto; consideraram-se algumas categorias à partida, e surgiram outras durante as análises (BARDIN, 1989). Na leitura fluente dos protocolos, emergiram denominadores comuns nas respostas que foram organizados em temas e categorias. Os temas eram: a organização da aprendizagem, o desenvolvimento das competências das crianças e a investigação como meio de formação. Do primeiro tema faziam parte as categorias: explorar diferentes abordagens à aprendizagem; tornar a aprendizagem lúdica em vez de a escolarizar; incluir conteúdos formais na área do conhecimento do mundo ${ }^{2}$; promover a reflexão perante as difıculdades; diversificar as áreas de conteúdo; promover a regulação das atividades diárias; e abordar emoções através da música e dramatização. No segundo tema, integraram-se: proporcionar um desenvolvimento integro; promover a participação social e na aprendizagem; andaimar escolhas; modelar comportamentos; respeitar o desenvolvimento individual, potenciando-o; envolver emocional/motivacionalmente as crianças; e aprender a relacionar-se socialmente. As notas de campo foram organizadas a partir do registro sistemático das biografias e transformadas em indicadores (frases simples e contextualizadas que descreviam um comportamento ou verbalização). Os indicadores foram organizados em conjuntos que remetiam para a rotina de sala: atividades em pequenos grupos (as crianças desenvolvem diferentes tarefas agrupadas em áreas temáticas), atividades em grande grupo (mais dirigidas pela educadora) e outras atividades (momentos observados fora de sala). Os indicadores foram avaliados segundo as dimensões de autorregulação (BRONSON, 2000): controle emocional e comportamental, controle cognitivo, atitudes prossociais e motivação para a autorregulação. A avaliação foi efetuada num sistema de categorização mutuamente exclusivo, na íntegra por um perito e 20\% por um juiz externo. 0 alfa de Cronbach para o acordo interjuízes foi de .823 .

\section{Resultados e discussão}

\section{Percepções e práticas na educação pré-escolar}

Nesta investigação, pretendíamos compreender as percepções dos educadores sobre a autorregulação e conhecer as práticas que promovem oportunidades para as crianças autorregularem as suas tarefas. Durante as entrevistas, respeitar o desenvolvimento individual, potenciando-o foi o aspecto sobre o desenvolvimento das crianças mais referido pelas educadoras. Foi tecido menor número de considerações sobre como dispor os espaços da sala para promover a aprendizagem autônoma e abordar emoções através da música e dramatização, assim como, modelar comportamentos e aprender a relacionar-se socialmente.

Do total dos 739 indicadores de oportunidades de autorregulação observados (Tabela 2), 279 diziam respeito a atividades em pequenos grupos (PG), 389 indicadores relacionavam-se com atividades em grande grupo (GG) e 71 remetiam para outras atividades (0). 0 contexto D foi onde se verificou maior número de indicadores no geral (265), nas

2- Área do conhecimento do mundo é uma área integradora de diferentes saberes, em que se procura que a criança adote uma atitude de questionamento e de procura organizada do saber, própria da metodologia científica, de modo a promover uma melhor compreensão do mundo físico, social e tecnológico que a rodeia (MINISTÉRIO DA EDUCAÇÃO, 2016). 
dimensões controle emocional e cognitivo (104) e controle cognitivo (97). Mas foi no contexto B que se identificaram mais indicadores de atitudes prossociais (26) e motivação para a autorregulação (66). Houve uma predominância de controle emocional e cognitivo e de controle cognitivo, comparativamente a atitudes prossociais e a motivação para a autorregulação em todos os contextos e nos três tipos de atividades. As oportunidades referentes a atitudes prossociais foram as menos observadas, no geral.

Tabela 2 - Quantidade de indicadores observados

\begin{tabular}{|c|c|c|c|c|c|c|c|c|c|c|c|c|c|c|c|c|c|}
\hline & & \multicolumn{4}{|c|}{ Contexto A } & \multicolumn{4}{|c|}{ Contexto B } & \multicolumn{4}{|c|}{ Contexto C } & \multicolumn{4}{|c|}{ Contexto D } \\
\hline & $\begin{array}{c}\text { Total de } \\
\text { indicadores }\end{array}$ & $P G$ & $\mathrm{GG}$ & 0 & Totais & $P G$ & $\mathrm{GG}$ & 0 & Totais & $P G$ & $\mathrm{GG}$ & 0 & Totais & $P G$ & $G G$ & 0 & 'Totais \\
\hline $\begin{array}{c}\text { Total de } \\
\text { indicadores }\end{array}$ & 739 & 79 & 11 & 25 & 115 & 70 & 125 & 10 & 205 & 80 & 61 & 13 & $154 \vdots$ & 50 & 192 & 23 & 265 \\
\hline CEC & 235 & 24 & 6 & 10 & 40 & 18 & 20 & 5 & 43 & 16 & 26 & 8 & 50 & 9 & 81 & 14 & 104 \\
\hline $\mathrm{CC}$ & 250 & 37 & 3 & 6 & 46 & 19 & 47 & 4 & 70 & 20 & 15 & 2 & 37 & 15 & 77 & 5 & 97 \\
\hline$A P$ & 79 & 4 & 2 & 6 & 12 & 9 & 16 & 1 & 26 & 11 & 3 & 3 & 17 & 10 & 13 & 1 & 24 \\
\hline MA & 173 & 14 & 0 & 3 & 17 & 24 & 42 & 0 & 66 & 33 & 17 & 0 & 50 & 16 & 21 & 3 & 40 \\
\hline \multicolumn{4}{|c|}{ Total indicadores PG 279} & & \multicolumn{6}{|c|}{ Total indicadores GG 389} & & \multicolumn{6}{|c|}{ Total indicadores 071} \\
\hline
\end{tabular}

Fonte: dados da pesquisa.

\section{Dimensões de autorregulação, categorias e indicadores}

$\mathrm{Na}$ triangulação dos dados, elaboraram-se mapas conceituais que associaram as dimensões de autorregulação com as categorias das entrevistas e os indicadores das observações. Em relação à dimensão controle emocional e comportamental (Figura 2), destacou-se a importância de se proporcionar um desenvolvimento íntegro, que inclui o cumprimento de regras e a adequação comportamental das crianças. Envolver emocional/motivacionalmente as crianças e abordar as emoções através da música e da dramatização foram outros aspectos sublinhados pelas educadoras como centrais para a promoção diária da aprendizagem.

Figura 2 - Resultados na dimensão controle emocional e comportamental

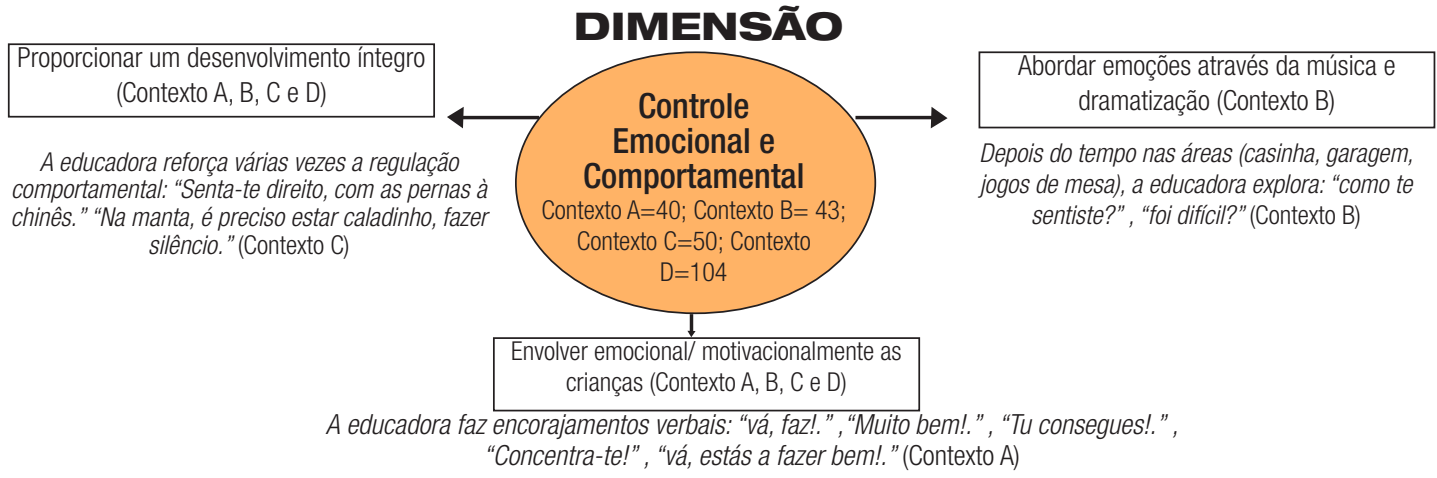

Legenda: Total de indicadores observados na dimensão controle emocional e comportamental; categorias das entrevistas e exemplo de indicadores correspondentes. Fonte: dados da pesquisa. 
Na dimensão controle cognitivo (Figura 3), emergiram assuntos relacionados com a exploração de diferentes abordagens à aprendizagem e a diversificação das áreas de conteúdo, que remetem para a manipulação de objetos com diferentes objetivos. Outro aspecto que as educadoras referiram acerca da abrangência dos conteúdos curriculares prevê a inclusão de conteúdos formais na área do conhecimento do mundo.

Figura 3 - Resultados na dimensão controle cognitivo

\section{DIMENSÃO}

Explorar diferentes abordagens à aprendizagem (Contexto $\mathrm{A} \mathrm{e} \mathrm{C}$ )

As crianças exploram os jogos de diferentes maneiras: "Agora já não é encontrar os pares. eu tiro uma peça e vocês adivinham." (Contexto C)

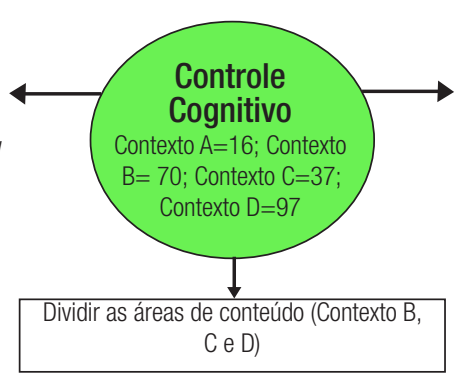

Incluir conteúdos formais na área do conhecimento do mundo (Contexto B, C e D)

A propósito do projeto sobre aviões, simulam uma viagem: o que colocar na mala? Quantas pessoas podem ir? Como é o percurso no aeroporto? 0 que acontece dentro de um aviação? (Contexto B)

No espaço exterior, a educadora organiza exercícios de expressão motora, montando circuitos de obstáculos que as crianças devem ultrapassar. (Contexto D)

Legenda: Total de indicadores observados na dimensão controle cognitivo; categorias das entrevistas e exemplo de indicadores correspondentes.

Fonte: dados da pesquisa.

No que se refere às atitudes prossociais (Figura 4), os temas remetem para as oportunidades que são dadas às crianças de desenvolveram a relação interpessoal, sobretudo com os pares. Assim se destacaram as necessidades de tornar a aprendizagem lúdica em vez de a escolarizar, de promover a participação social e na aprendizagem e de aprender a relacionar-se socialmente.

Figura 4 - Resultados na dimensão atitudes prossociais

\section{Tornar a aprendizagem lúdica em vez de a escolarizar (Contexto A, B e C)}

Em pares, as crianças escrevem uma mensagem no teclado do computador: um dita ao outro el ou vai tapando as letras que o colega já digitou. (Contexto D)

\section{DIMENSÃO}

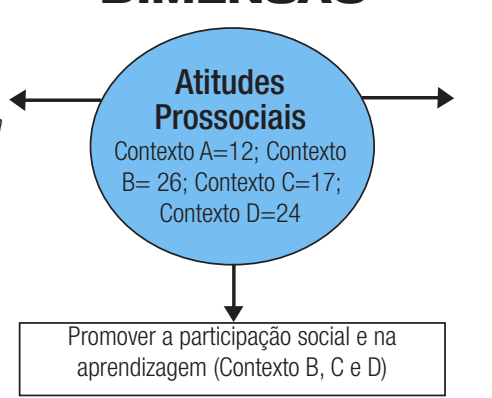

As três crianças fazem uma grande construção conjunta, negociam que peças adicionar.

$$
\text { (Contexto D) }
$$

Comentam o trabalho dos colegas. (Contexto B)
Aprender a relacionar-se socialmente (Contexto C)

Perante um desentendimento, a educadora recomenda às crianças: "Conversem e tentem resolver o assunto sozinhos" (Contexto C)

Legenda: Total de indicadores observados na dimensão atitudes prossociais; categorias das entrevistas e exemplo de indicadores correspondentes.

Fonte: dados da pesquisa. 
Relativamente à dimensão motivação para a autorregulação (Figura 5), destacouse a importância de particularizar, sempre que possível, a abordagem à aprendizagem de cada criança, o que implica respeitar o desenvolvimento individual, potenciando-o. As educadoras sublinharam igualmente o fato de ser preciso promover tanto a regulação das atividades diárias como a reflexão perante as dificuldades.

Figura 5 - Resultados na dimensão motivação para a autorregulação

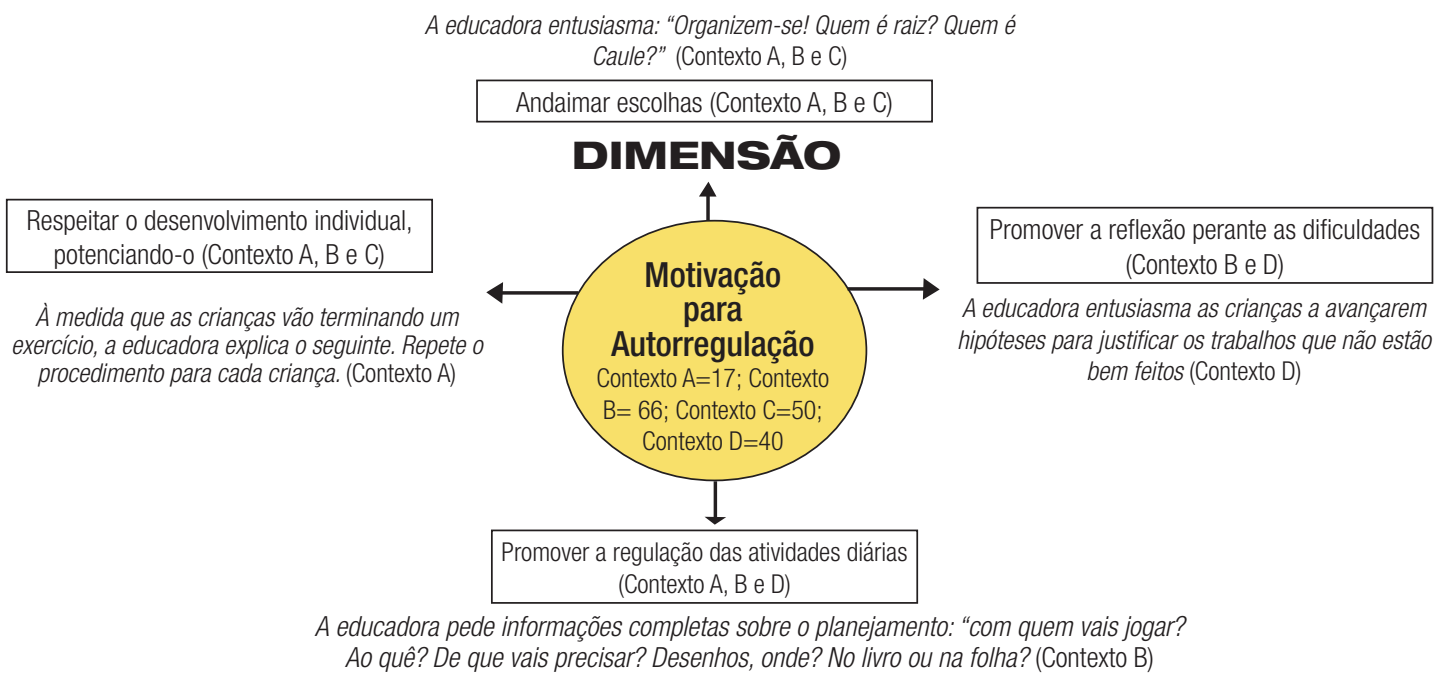

Legenda: Total de indicadores observados na dimensão motivação para a autorregulação; categorias das entrevistas e exemplo de indicadores correspondentes. Fonte: dados da pesquisa.

Todas as educadoras referiram o interesse em participar nesta investigação enquanto reforço da sua formação profissional, como ilustram as citações: "Há muito por melhorar [...] a evoluir como profissionais e como pessoas" (contexto B); "É sempre bom um olhar de fora que nos alerte para as situações, que a gente possa conversar, partilhar ideias." (contexto D).

\section{Estratégias pedagógicas e sua intencionalidade}

Compreendemos que, no domínio do meio físico e da organização da aprendizagem, as educadoras planificavam as atividades seguindo as Orientações Curriculares (MINISTÉRIO DA EDUCAÇÃO, 2016), optando frequentemente por uma metodologia indutiva que integrava a experiência e a curiosidade das crianças nas atividades. As profissionais referiram que é necessário criar oportunidades para proporcionar um desenvolvimento íntegro das crianças, como ilustra a citação: "Dentro das áreas de conteúdo, vamos definir objetivos, definir estratégias para as dificuldades encontradas no grupo. E essas dificuldades vão ser mais trabalhadas [...] tem que ser tudo trabalhado" (contexto D).

E é igualmente necessário envolverem as crianças emocional/motivacionalmente, como refere a citação: "Quando eu vejo que está a ser uma pressão muito grande, faz no 
dia a seguir [...] quero que elas aprendam o conteúdo daquela área, mas se emocionalmente elas também não estiverem bem..." (contexto A, excerto que remete para a dimensão controle emocional e comportamental).

Também se observaram oportunidades deste nível nos quatro contextos, o que vai ao encontro das metas de aprendizagem para o pré-escolar e reforça aspectos centrais do desenvolvimento da aprendizagem: o envolvimento das crianças no estabelecimento dos objetivos do dia, no planejamento das atividades, na informação sobre a acessibilidade de recursos de ajuda, na definição dos critérios de sucesso e avaliação e na discussão sobre como podem progredir, respeitando o percurso pessoal (CLARK, 2012).

As educadoras referiram frequentemente que a educação pré-escolar não deve ser sinônimo de escolarização, mas sim um tempo de promoção da literacia emergente de acordo com o interesse e ritmo das crianças (ONCUA; UNLUER, 2015; SANDVIK; DAAL; ADÈR, 2014), como compreendemos em: "0 meu objetivo principal não é que eles saibam o abecedário ou que saibam contar de 1 a 10." (contexto C); "Nem eu como educadora de infância tenho obrigação de ensinar a ler e a escrever." (contexto A).

Os momentos de promoção da relação socioemocional, observados por diversas vezes, tendiam a reforçar as competências autorregulatórias, mas também se relacionavam com percepções elevadas de autoeficácia das crianças e com o feedback formativo da educadora (BANDURA, 1997; MÄ̈̈TTÄ; JÄRVELÄ, 2013). A proximidade do adulto tornou-se, então, um reforço e um modelo no desenvolvimento da autorregulação nas crianças (PERELS et al., 2009). Complementarmente, os momentos de relação com os pares, sobretudo nas áreas temáticas, constituíram-se como oportunidades para adotar atitudes prossociais. De fato, a escola deve ser um lugar de experiências sociais (SANTOS; SILVA, 2016), mas vai além disso, uma vez que a criação deste tipo de oportunidades se torna, muitas vezes, um incremento na motivação para a autorregulação.

Gráfico 1 - Número total de indicadores da dimensão motivação para a autorregulação em cada contexto

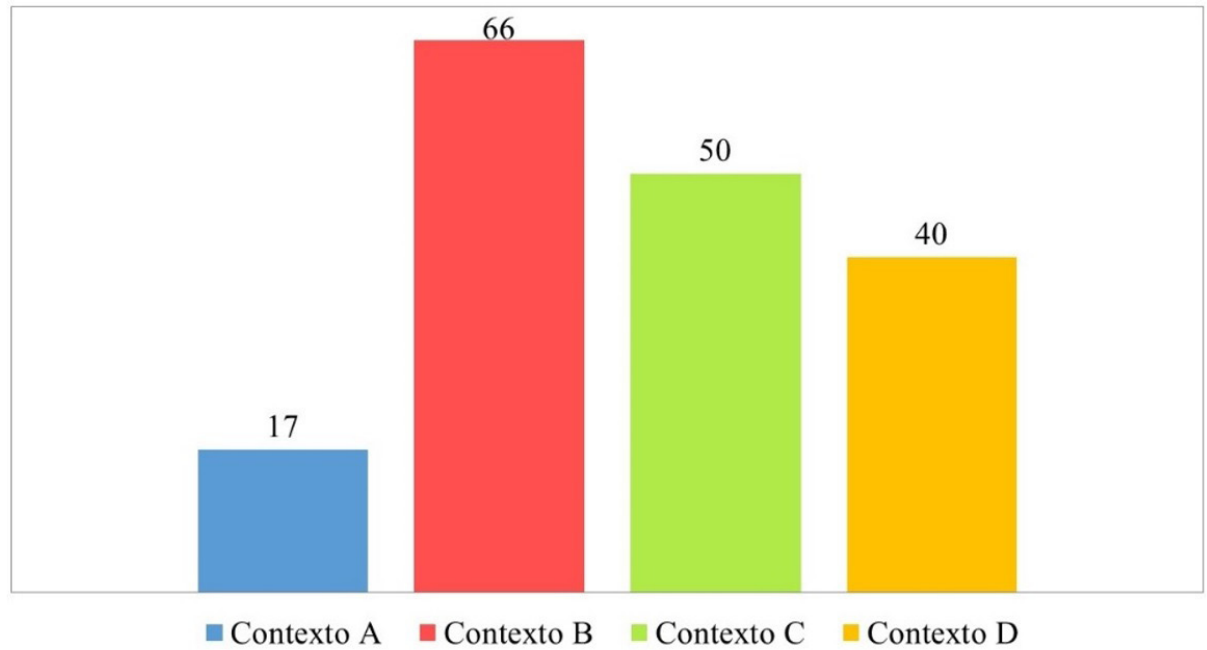

Fonte: dados da pesquisa. 
0 caminho da autonomia dado a percorrer às crianças é particularmente relevante no modo como lhes é permitido se apropriarem das tarefas. 0 recurso ao private speech é mais evidente no tempo em pequenos grupos: a necessidade de recordar a si mesmo qual o objetivo a alcançar e quais os meios a mobilizar indicam o desenvolvimento da consciência metacognitiva (ZIMMERMAN, 2013) - dimensão controle cognitivo. 0 número de indicadores de motivação para a autorregulação do contexto B (Gráfico 1) pode contribuir para traçar considerações sobre a maturidade do grupo, já que todas as crianças têm 5 anos (contrariamente aos grupos multietários), mas a maioria das oportunidades desta dimensão foram observadas nas atividades em grande grupo (Tabela 2). Assim, vale a pena salientar a metodologia da educadora: "Um tempo específico da nossa rotina diária que é planear, fazer, rever."

Dos quatro contextos, o contexto B é o único onde decorre um ensino explícito de estratégias de planejamento (SÁIZ; CARBONERO; ROMÁN, 2014; VEIGA SIMÃO, 2013). Já no contexto $C$, apesar de se ter observado um número considerável de indicadores de motivação para a autorregulação, a educadora não referiu a regulação das atividades diárias como uma prática recorrente. Todavia, as crianças têm oportunidade de escolher, duas vezes por dia, a atividade que pretendem realizar; os seus objetivos e meios são, como já vimos, particularmente autorregulados nestes momentos. Mas esta prática não parece ser intencional. 0 reforço emocional e a relação social são muito encorajados com o grupo de crianças e o tempo nas áreas temáticas é, por excelência, propício a tais oportunidades, como ilustra a citação: "Eu valorizo muito a relação. Acho que nesta idade é isso que fica" (contexto C).

De fato, em todos os contextos se verificou a possibilidade de as crianças escolherem a área onde vão brincar. Os materiais didáticos e a sua localização cumprem também uma função pedagógica, previamente determinada pelas educadoras, contrariando outras realidades onde a utilização dos brinquedos é pouco ponderada (KISHIMOTO, 2001).

\section{Graus de liberdade na autorregulação de tarefas da educação pré-escolar}

Na educação pré-escolar, as oportunidades devem permitir às crianças decidirem, em graus cada vez mais elevados, o quê, por quê, como, onde, quando e com quem desenvolvem as suas tarefas (Figura 6), ao invés de lhes serem prescritas atividades pelos educadores, por vezes pouco flexíveis (VEIGA SIMÃO, 2012). Estes graus efetivos de liberdade poderão proporcionar o desenvolvimento da aprendizagem do seguinte modo:

0 quê? (dimensão das meta-aprendizagens ou objetivos de aprendizagem) 0 educador pode proporcionar oportunidades às crianças para optarem entre um vasto leque de hipóteses, como as áreas temáticas na sala. 0 adulto deve encorajar escolhas conscientes e intencionais nas várias atividades disponíveis que podem enriquecer a aprendizagem. Muitas crianças podem sentir-se perdidas entre tantas possibilidades e, por isso, o educador tem um papel essencial, não só em corresponder ao agrado da criança, mas também a promover atividades que desenvolvam as suas competências e conhecimento. 
Figura 6 - Graus de liberdade na autorregulação de tarefas da educação pré-escolar

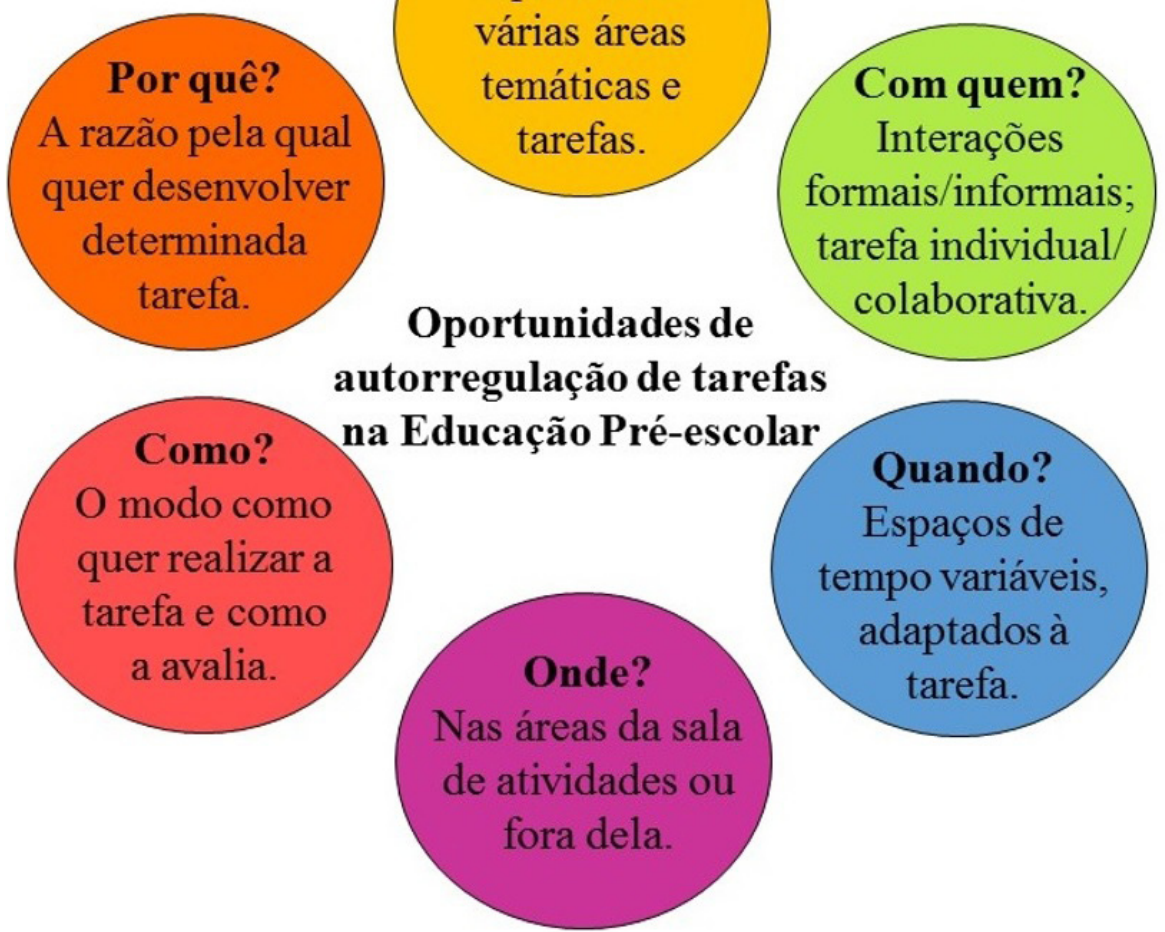

Fonte: dados da pesquisa com base em Veiga Simão, 2012.

Um exemplo sobre a diversificação do tipo de tarefas a abordar pelas crianças acontece no contexto $\mathrm{C}$, onde as crianças experienciam duas áreas diferentes no mesmo dia.

Por outro lado, os educadores podem levar as crianças a se perguntarem sobre o que estão a desenvolver em determinada tarefa. Este autoquestionamento, decorrendo dos objetivos e controle das crianças, é essencial na automonitorização, autojulgamento, controle da ação e volição que são, entre outros, processos autorregulatórios.

Por quê? (dimensão da intencionalidade, do motivo) 0 papel do adulto deve ser o de promover oportunidades para as crianças encontrarem a razão pela qual querem desenvolver determinada tarefa, ou seja, levá-las a refletir sobre a justificação da sua escolha. Num momento observado no contexto $B$, a educadora pediu às crianças que ilustrassem uma refeição; enquanto o faziam, a educadora ia questionando: "Porque escolheste esses alimentos? Porque os desenhas dessa forma?".

Como? (dimensão da decisão estratégica e das escolhas do método) 0 educador pode dar oportunidade às crianças de, por exemplo, escolher a área, os pares com quem 
pretendem interagir e os materiais a usar. A singularidade ou multiplicidade dos ambientes de aprendizagem onde as crianças desenvolvem o conhecimento e as suas competências depende, assim, delas próprias. Na presente investigação, este aspecto é particularmente saliente nos momentos em que as crianças escolhem a área e os colegas com quem brincam para dar continuidade a uma tarefa iniciada anteriormente. Daqui decorre a importância do planejamento estratégico e dos processos autorregulatórios relacionados.

Onde? (dimensão contextual da aprendizagem) Este aspecto refere-se à transversalidade dos ambientes de aprendizagem que podem ser potenciados pelos educadores. 0 fato de considerarmos, aqui, outras atividades é prova disso mesmo: uma ida à biblioteca, uma visita de estudo ou uma experiência científica fora da sala são oportunidades que facilitam a partilha, a colaboração e as atitudes prossociais. Não obstante a validade destas atividades maioritariamente propostas pelos educadores, as crianças devem ser envolvidas na sua escolha, na organização e na estruturação do ambiente.

Quando? (dimensão temporal da aprendizagem) A aprendizagem desenvolve-se num maior ou menor espaço de tempo e os resultados desejados podem estar próximos ou requerer um período de tempo alargado. Considerando este fato, os educadores devem propor às crianças desafios que sejam temporalmente diferentes. No contexto C, faz-se o registo do fim de semana à segunda-feira. É expectável que as crianças desempenhem esta tarefa no espaço de tempo correspondente àquele dia. Já o trabalho de grupo sobre os planetas, desenvolvido no contexto B, foi concluído ao longo da semana. Sobretudo em tarefas que integram diversos momentos (no trabalho de grupo: escolha do tema, pesquisa, seleção da informação, preparação do suporte de apresentação, ensaio e apresentação em grupo), a necessidade de desenvolver estratégias de controle do tempo é um ponto crítico para uma gestão eficaz.

Mas este aspecto relaciona-se também com o desenvolvimento e a maturidade emocional das crianças, uma vez que é necessário respeitar os ritmos de realização de cada um em tarefas idênticas. Por exemplo, quando da realização da prenda do dia do pai (contexto D) e na elaboração de grafismos (contexto A), as educadoras oportunizaram a motivação para a autorregulação, sublinhando o planejamento e a gestão do tempo como processos autorregulatórios essenciais.

Com quem? (dimensão social da aprendizagem) Os educadores podem dar oportunidade às crianças de escolher, por exemplo, entre desenvolver a sua aprendizagem através de interações formais ou informais, com o educador ou os pares. As escolhas que as crianças fazem em relação a estarem sozinhas ou interagirem de forma colaborativa relacionam-se com a forma como elas próprias percebem a aprendizagem. Elas podem perceber o adulto com diferentes papéis: alguém a quem eu posso recorrer para pedir ajuda ou alguém que, simplesmente, está presente, mas a quem eu raramente recorro. Este aspecto pode, inclusivamente, influenciar a aprendizagem e a forma como as crianças regulam as tarefas.

Nos quatro contextos estudados, as educadoras assumem um papel de recurso no tempo das áreas temáticas, interferindo o menos possível e permitindo a interação livre entre as crianças, que reforça a percepção de um ambiente socialmente inclusivo. Neste 
caso, os processos autorregulatórios estão relacionados, por exemplo, com a seleção de modelos e a procura de ajuda.

\section{Considerações finais}

Esta investigação foi uma oportunidade de reflexão acerca da educação pré-escolar em Portugal, tendo pretendido conhecer as percepções dos educadores sobre as práticas que promovem a autorregulação de tarefas e identificar as práticas educativas que criam oportunidades para as crianças autorregularem as tarefas.

Uma vez que nos sistemas de educação formal os objetivos de aprendizagem são necessários, os educadores devem procurar promover graus de liberdade e oportunidades para os aprendentes efetuarem tomadas de decisão pessoais. Elas são centrais para que as crianças possam regular o seu processo de aprendizagem. É tarefa dos educadores explorar os objetivos pedagógicos adaptados a cada faixa etária e compreender que a sua mera aplicação não significa necessariamente que as crianças estão a construir conhecimento. Assim, os educadores devem estar preparados para reconstruir e refletir sobre a sua prática, articulando diferentes interesses e necessidades das crianças, contextos, realidades e a sua intencionalidade pedagógica (MONÇÃO, 2017). Como educadores, num sentido mais lato, devem estar atentos à direção dada às tarefas educacionais e às metas a alcançar.

Por forma a dar uma resposta adequada aos objetivos pedagógicos, consideramos que a proporção adultos/crianças em sala deveria ser revista no âmbito da legislação em vigor. Foi evidente o efeito do reforço emocional na relação entre crianças e adultos, já que a relação de maior proximidade se constituiu num aumento da percepção de autoeficácia das crianças. Por outro lado, um trabalho diferenciado em pequenos grupos parece permitir uma melhor monitorização por parte do adulto e a criação de mais oportunidades de regulação das tarefas pelas crianças. Compreendemos ainda a necessidade de formação contínua dos educadores de infância sobretudo na área da promoção de competências autorregulatórias. As participantes reconheceram nesta iniciativa uma oportunidade para serem acompanhadas na sua experiência profissional. Refletindo sobre as estratégias de ensino e aprendizagem, o seu percurso pessoal e as expectativas de futuro, receberam feedback sobre as suas percepções e práticas.

Assumimos algumas limitações que decorrem dos critérios definidos pelos investigadores neste estudo. Assim, ainda que se pudesse ponderar a inclusão de mais um observador ou a utilização de equipamentos vídeo e/ou áudio, não se pode desconsiderar o investigador como um elemento imbuído no contexto. Só através da familiaridade com a rotina dos grupos foi possivel confirmar os dados e tornar esta metodologia transferivel para outros contextos, na medida em que se procurou compreender as percepções e comportamentos dos participantes. Como sugestões de futuro, pode equacionar-se a formação de equipes de intervisão ou de articulação com outras entidades para promover a reflexão-ação sobre as práticas na educação pré-escolar. 


\section{Referências}

AMAD0, João; FERREIRA, Sónia. A entrevista na investigação educacional. In: AMAD0, João (Coord.). Manual de investigação qualitativa em educação. Coimbra: Imprensa da Universidade de Coimbra, 2013. p. 207-232.

AMADO, João; FREIRE, Isabel. Estudo de caso na investigação em educação. In: AMADO, João (Coord.). Manual de investigação qualitativa em educação. Coimbra: Imprensa da Universidade de Coimbra, 2013. p. $121-143$

BANDURA, Albert. Self-Efficacy: The exercise of control. New York: Freeman, 1997.

BARDIN, Laurence. L'analyse de contenu. Paris: Presses Universitaires de France, 1989.

BECKER, Dereck et al. Physical activity, self-regulation, and early academic achievement in preschool children. Early Education and Development, London, v. 25, n. 1. p. 56-70, 2014. D0l: 10.1080/10409289.2013.780505.

BRONSON, Martha. Supporting self-regulation in preschool and kindergarten children. In: BRONSON, Martha. Self-regulation in early childhood: nature and nurture. New York: Guilford Press, 2000. p. 198-220.

BROSTRÖM,Stig etal.Preschool teachers' views on children'slearning: an international perspective. Early Child Development and Care, London, v. 185, n. 5, p. 824-847, 2015. D0l: 10.1080/03004430.2014.958483.

BRYCE, Donna; WHITEBREAD, David; SZÜCS, Dénes. The relationships among executive functions, metacognitive skills and educational achievement in 5 and 7 year-old children. Metacognition and Learning, New York, v. 10, n. 2, p. 181-198, 2014. D0l: 10.1007/s11409-014-9120-4.

BULUT PDÜK, Senay; YILDIZBAS, Füsun; AYGUN, Lecturer. Investigations of preschool teachers' opinion about physical/spatial characteristics of preschool classrooms in preschool education institutions. Social and Behavioral Sciences, Amsterdã, v. 143, p. 750-757, 2014. DOl: 10.1016/j.sbspro.2014.07.427.

CLARK, lan. Formative assessment: assessment is for self-regulated learning. Education Psychology Review, New York, v. 24, n. 2, p. 205-249, 2012. D0l: 10.1007/s10648-011-9191-6.

CUETO, Santiago; LÉON, Juan; MIRANDA, Alejandra. Classroom composition and its association with students' achievement and socioemotional characteristics in Peru. Assessment in Education, London, v. 23, n. 1, p. 126-148, 2016. DOl: 10.1080/0969594X.2015.1105783.

DEMIRTAS, Vesile. Self-regulation strategies of the six-year-old pre-school children. International Journal of Academic Research Part B, Baku, v. 5, n. 2, p. 264-273, 2013. D0l: 10.7813/2075-4124.2013/5-2/B.42.

FERNANDES, Ana. Perceções dos educadores de infância acerca dos comportamentos de autorregulação das crianças. 2012. Dissertação (Mestrado em Educação) - Instituto de Educação, Universidade de Lisboa, Lisboa. 2012. 
FUHS, Mary et al. Preschool classroom processes as predictors of children's cognitive self-regulation skills development. School Psychology Quarterly, Washington, DC, v. 28, n. 4, p. 347-359, 2013. D0I: 10.1037/ spq0000031.

GROTH, Randall. Situating qualitative modes of inquiry within the discipline of statistics education research. Statistics Education Research Journal, Wellington, DC, v. 9, n. 2, p. 7-21. 2010.

HADLEY, Fay; WANIGANAYAKE, Manjula; SHEPHERD, Wendy. Contemporary practice in professional learning and development of early childhood educators in Australia: reflections on what works and why. Professional Development in Education, London, v. 41, n. 2, p. 187-202, 2015. D0I: 10.1080/19415257.2014.986818.

HARRIS, Karen. Developing self-regulated learners: the role of private speech and self-instructions. Educatinal Psychologist, London, v. 25, n. 1, p. 35-49. 1990.

HUBERT, Blandine et al. Indirect and direct relationships between self-regulation and academic achievement during the nursery/elementary school transition of French students. Early Education and Development, London, v. 26, n. 5-6, p. 685-707, 2015. D0I: 10.1080/10409289.2015.1037624.

KISHIMOTO, Tizuko Morchida. Brinquedos e materiais pedagógicos nas escolas infantis. Educação e Pesquisa, São Paulo, v. 27, n. 2, p. 229-245, 2001.

KONTOS, Susan. Preschool teachers' talk, roles, and activity settings during free play. Early Childhood Research Quarterly, Amsterdã, v. 14, n. 3, p. 363-382, 1999.

KOPP, Claire. Antecedents of self-regulation: a developmental perspective. Developmental Psychology, Washington, v. 18, n. 2, p. 199-214, 1982.

LOPES DA SILVA, Adelina. Auto-instrução: suas aplicações clínicas e educacionais. Revista Portuguesa de Psicologia, Lisboa, v. 22, p. 133-172. 1985.

MÄÄTTÄ, Elina; JÄRVELÄ, Sanna. Involving children in reflective discussions about their perceived selfefficacy and learning experiences. International Journal of Early Years Education, London, v. 21, n. 4, p. 309-324, 2013. DOI: 10.1080/09669760.2013.867836.

MARTIN, Linda; KRAGLER, Sherry. Early signs of self-regulating print: kindergartners at work reading to understand fiction and nonfiction text. Journal of Research in Childhood Education, London, v. 26. p. 141153, 2012. DOI: 10.1080/02568543.2012.659648.

MASOUMI, Davoud. Preschool teachers' use of ICTs: Towards a typology of practice. Contemporary Issues in Early Childhood, Thousand Oaks, v. 16, n. 1, p. 5-17, 2015. DOl: 10.1177/1463949114566753.

MCCLELLAND, Megan; WANLESS, Shannon. Introduction to the special issue: self-regulation across different cultural contexts. Early Education and Development, London, v. 26, n. 5-6, p. 609-614, 2015. D0I: 10.1080/10409289.2015.1039436. 
MCCLINTIC, Sandra; PETTY, Karen. Exploring early childhood teachers' beliefs and practices about preschool outdoor play: a qualitative study. Journal of Early Childhood Teacher Education, London, v. 36, n. 1, p. 24-43, 2015. DOl: 10.1080/10901027.2014.997844.

MINISTÉRIO DA EDUCAÇÃO. Direção Geral de Educação. Orientações curriculares para a educação préescolar, Lisboa: ME, 2016. Disponível em: <http://www.dge.mec.pt/ocepe/sites/default/files/Orientacoes_ Curriculares.pdf>. Acesso em: 10 mar. 2017.

MINISTÉRIO DA EDUCAÇÃO. Direção Geral de Inovação e Desenvolvimento Curricular. Metas de aprendizagem para a educação pré-escolar, Lisboa: ME, 2010. Disponível em: <http://metasdeaprendizagem.dge.mec. pt/metasdeaprendizagem.dge.mec.pt/educacao-pre-escolar/apresentacao/index.html>. Acesso em: 10 mar. 2017.

MONÇÃO, Maria Aparecida. Cenas do cotidiano na educação infantil: desafios da integração entre cuidado e educação. Educação e Pesquisa, São Paulo, v. 43, n. 1, p. 161-176, 2017. D0l: 10.1590/S15179702201608147080.

ONCUA, Elif; UNLUER, Esra. Examination of preschool teachers' approaches to early literacy. Social and Behavioral Sciences, Amsterdã, v. 191, p. 1043-1047, 2015. D0I: 10.1016/j.sbspro.2015.04.656.

PECK, Nancy; MAUDE, Susan; BROTHERSON, Mary Jane. Understanding preschool teachers' perspectives on empathy: a qualitative inquiry. Early Childhood Educational Journal, v. 43, p. 169-179, 2015. D0I: 10.1007/s10643-014-0648-3.

PERELS, Franzinka et al. Improving self-regulated learning of preschool children: evaluation of training for kindergarten teachers. British Journal of Educational Psychology, London, v. 79, p. 311-327, 2009.

PERRY, Nancy; VANDEKAMP, Karen. Creating classroon contexts that support young children's development of self-regulated learning. International Journal of Educational Research, Amsterdã, v. 33, n. 7/8, p. 821843, 2000.

PISCALHO, Isabel; VEIGA SIMÃO,Ana Margarida. Promover competências autorregulatórias da aprendizagem nas crianças dos 5 aos 7 anos: perspetivas de investigadores e docentes. Interacções, Santarém, v. 10, n. 30, p. 72-109, 2014a.

PISCALHO, Isabel; VEIGA SIMÃO, Ana Margarida. Promoção da autorregulação da aprendizagem das crianças: proposta de instrumento de apoio à prática pedagógica. Nuances, São Paulo, v. 25 n. 3, p. 170190, 2014b.

PORTUGAL. Lei n. ${ }^{\circ}$ 5/97, de 10 de fevereiro - Lei-Quadro da Educação Pré- Escolar. Diário da República Portuguesa, Lisboa, I Série-A. n. 34, 1997a.

PORTUGAL. Decreto-Lei n. ${ }^{0}$ 147/97, de 11 de junho (regime jurídico do desenvolvimento e expansão da educação pré-escolar, sistema de organização e financiamento). Diário da República Portuguesa, Lisboa, I Série-A. n. 133, 1997b. 
RENTZOU, Konstantina. The quality of the physical environment in private and public infant/toddler and preschool Greek day-care programmes. Early Child Development and Care, London, v. 184, n. 12, p. 18611883, 2014. DOI: 10.1080/03004430.2014.891991.

ŞAHIN, Ece; DOSTOĞLU, Neslihan. Evaluation of kindergarten group rooms in the context of size: children and teacher's perspective in Turkey. European Journal of Contemporary Education, Bratislava-Nove Mesto, v. 10, n. 4, p. 253-264, 2014. D0l: 10.13187/ejced.2014.10.253.

SÁlZ, Maria; CARBONERO, Miguel-Ángel; ROMÁN, José-Maria. Aprendizaje de habilidades de autorregulación en niños de 5 a 7 años. Universitas Psychologica, Bogotá, v. 13, n. 1, p. 2-23, 2014. D0I:10.11144/Javeriana.UPSY13-1.ahan.

SANDVIK, Jenny; DAAL, Victor; ADĖR, Herman. Emergent literacy: Preschool teachers' beliefs and practices. Journal of Early Childhood Literacy, New York, v. 14, n. 1, p. 28-52, 2014. D0I:10.1177/1468798413478026.

SANTOS, Sandro; SILVA, Isabel. Crianças na educação infantil: a escola como lugar de experiência social. Educação e Pesquisa, São Paulo, v. 42, n. 1, p. 131-150, 2016. D0l: 10.1590/S1517-9702201603137189.

SKIBBE, Lory et al. Schooling effects on preschoolers' self-regulation, early literacy, and language growth. Early Childhood Research Quarterly, London, v. 26, n. 1, p. 42-49, 2011.

VEIGA SIMÃO, Ana Margarida. Aprendizagem estratégica: uma aposta na auto-regulação. Lisboa: Ministério da Educação. 2002.

VEIGA SIMÃO, Ana Margarida. Ensinar para a aprendizagem escolar. In: VEIGA, Feliciano (Org.) Psicologia da educação: teoria, investigação e aplicação. Lisboa: Climepsi, 2013. p. 495-541.

VEIGA SIMÃO, Ana Margarida. Entrelaçar experiências narrativas com a autorregulação da aprendizagem. In: ABRAHÃO, Maria (Org.) Pesquisa (auto)biográfica em rede. Natal: Edufrn; Porto Alegre: Eplicrs; Salvador: Eduneb. 2012.(Pesquisa (Auto)biográfica - temas transversais). p. 113-140.

WHITEBREAD, David; COLTMAN, Penny. Aspects of pedagogy supporting metacognition and mathematical learning in young children; evidence from an observational study. ZDM The International Journal on Mathematics Education, Berlim, v. 42, n. 2, p. 163-178, 2010.

WHITEBREAD, David et al. The development of two observational tools for assessing metacognition and self-regulated learning in young children. Metacognition and Learning, New York, v. 4, n. 1, p. 63-85, 2009. DOl: 10.1007/s11409-008-9033-1.

WILLIFORD, Amanda et al. Children's engagement within the preschool classroom and their development of self-regulation. Early Education and Development, Oxford, v. 24, n. 2, p. 162-187. 2013. D0I: 10.1080/10409289.2011.628270.

WOOD, Elizabeth; BENNETT, Neville. "I know what l've got better at": young children's understanding of progression in their learning'. Artigo apresentado na European Association for Research on Learning and Instruction, University of Fribourg, Switzerland, ago. 2001. 
YIN, Robert. Case study research: design and methods. London: Sage, 2009.

ZIMMERMAN, Barry. From cognitive modeling to self-regulation: a social cognitive career path. Educational Psychologist, New Jersey, v. 48, n. 3, p. 135-147, 2013.

Recebido em: 20.12.2017

Revisões em: 20.02.2018

Aprovado em: 03.04.2018

Janete Silva Moreira é doutoranda em Psicologia, na especialidade de Psicologia da Educação e bolseira de investigação pela Fundação para a Ciência e Tecnologia (SFRH/ BD/137715/2018). Colabora no Centro de Investigação em Ciência Psicológica (CICPSI) da Faculdade de Psicologia da Universidade de Lisboa e é investigadora no Projeto de Estudos da Aprendizagem Autorregulada (PEAAR). Tem experiência como psicóloga educacional e formadora em projetos psicoeducativos.

Ana Margarida Veiga Simão é professora catedrática e membro do Conselho Científico da Faculdade de Psicologia da Universidade de Lisboa. Coordena a Seção de Psicologia da Educação e o Programa de Doutoramento Interuniversitário em Psicologia. É membro do CICPSI e coordenadora do PEAAR. 